\title{
A FURTHER CONTRIBUTION TO THE STUDY OF PYLORIC STENOSIS *
}

\author{
L. W. SAUER, M.D. \\ IEVANSTON, ILL.
}

The treatment of pyloric stenosis is a topic which is still very much under discussion. This is mainly due to the fact that some clinicians advocate immediate operation while others get excellent results in many cases without such a radical procedure. Good results are often obtained without surgery because the spasm frequently relaxes when certain dietary measures are instituted. Operation, soon after the diagnosis is made, doubtless subjects many infants to unnecessary operation. On the other hand, persistence in unsuccessful feeding may increase the surgical risk.

The statement occasionally made by some pediatricians that the diagnosis of pyloric stenosis is synonymous with indication for operation is not in accord with the opinion held by the foremost surgeons in this field. Thus Downes, ${ }^{1}$ points out very clearly that medical treatment is justifiable for a period of from seven to ten days, provided the patient does not lose too much weight ( 20 per cent. of the birth weight is the maximum weight loss he allows). Of the 163 cases of pyloric stenosis seen by Strauss ${ }^{2}$ only 107 patients (65 per cent.) were operated on. He treated the remaining fifty-six medically. He says: "Not a single one of the medically treated cases returned for operation."

Most workers agree that the Fredet ${ }^{3}$-Rammstedt ${ }^{4}$ operation, or a modification, is the best surgical procedure in those cases that fail to yield to proper medical treatment. It is true that some surgeons recommend immediate operative interference as soon as the symptoms of pyloric stenosis become manifest. Thus it has happened that on operation no tumor was found. ${ }^{5}$ The abdomen was closed without further interference. Such a procedure would be perfectly legitimate if it had been shown that nonoperative treatment could only be successful in a small number of cases. But such is not the case. Besides the results

* Received for publication May 7, 1921.

* From the Pediatric Department of the Evanston Hospital.

1. Downes: J. A. M. A. 75:228 (July 24) 1920.

2. Strauss: J. A. M. A. 75:232 (July 24) 1920.

3. Fredet: (Dufour and Fredet), Rev. de chir. 37:208, 1908.

4. Rammstedt: Med. Klin. 8:1702, 1912.

5. I do not wish to discuss here the appearance and disappearance of tumors which have been observed at the time of laparotomy. 


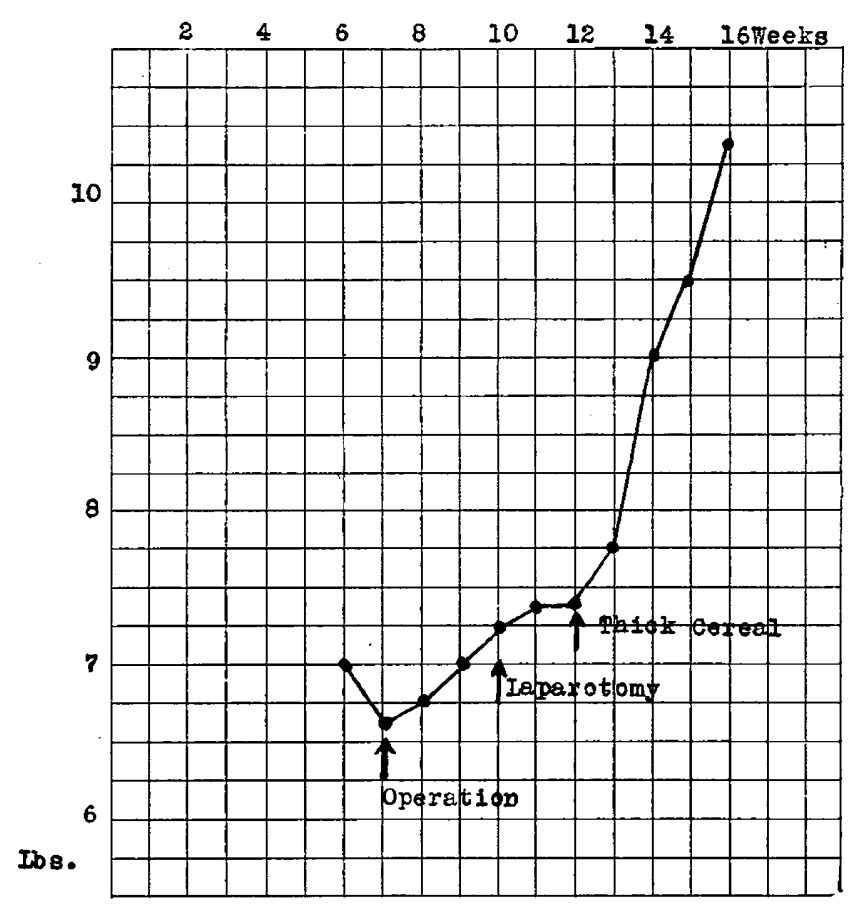

Figure 1.

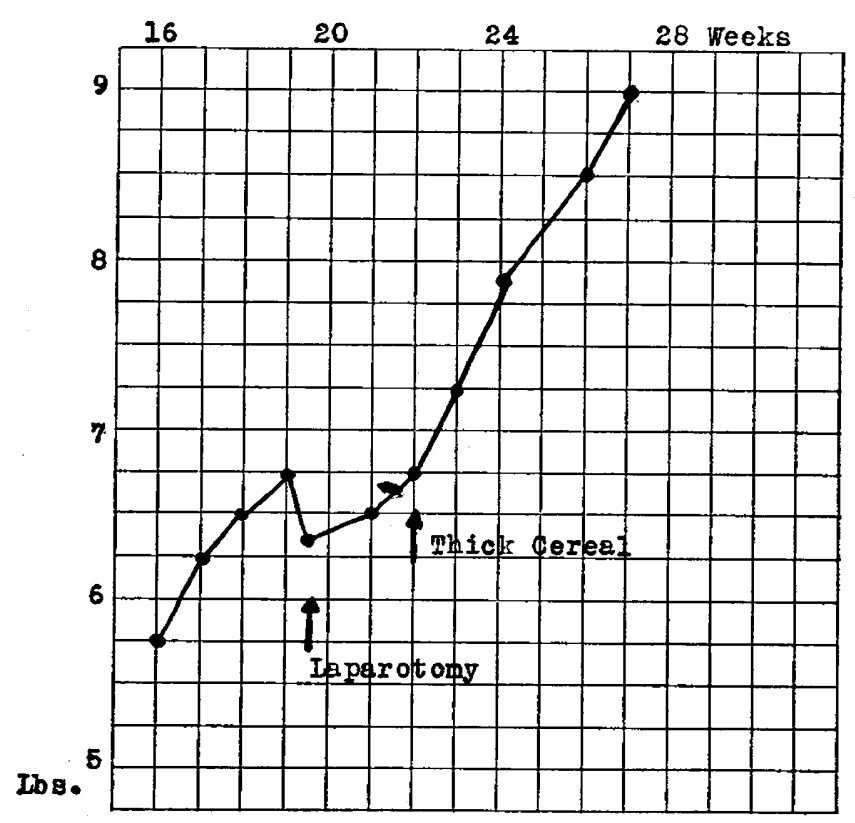

Figure 2 
of Strauss, those of Heubner, ${ }^{6}$ Ibrahim, ${ }^{7}$ Porter, ${ }^{8}$ Sedgwick, ${ }^{9}$ and among others my own lend very strong support to the statement of Downes in regard to the justification of medical treatment. Indeed, it would, perhaps, be more correct to say that, as long as the patient is doing fairly well an operation is only justifiable when medical treatment has proved of no avail. An experienced surgeon can do this operation with minimal risk. On the other hand, when done by one of insufficient experience, the mortality may be very high, even when the surgical risk was very small. I speak here from experience.

That nearly moribund cases are a bad risk for the surgeon as well as for the internist is self-evident. Of the 175 patients operated on by Downes thirty died. Eighteen died from collapse shortly following operation-all were in extremely poor condition. Four others had intestinal complications, five developed peritonitis, and the remaining three died of hemorrhage. Twenty-two of his patients continued to vomit in moderate degree, and in sixteen others the vomiting occurred in large amounts. Various surgeons warn of the danger of incising the duodenum with a resulting peritonitis. Lewis ${ }^{10}$ cautions that opening of the incision has occurred not infrequently when made in the linea alba. Of the twenty-two patients operated on by Hill, ${ }^{11}$ two had to have the abdomen reopened. In one of the cases the opening was inadequate, in the other, the wound broke open on the sixth day and on re-operating adhesions were found.

Two cases with severe symptoms of postoperative obstruction in which the Fredet-Rammstedt operation had been performed by skilled surgeons are of interest; so is a case in which the operation was inadequate as all the symptoms of pyloric stenosis persisted for weeks until thick cereal feedings were substituted for the breast milk feedings.

\section{REPORT OF CASES}

CASE 1.-(31) Alene T., was born Aug. 29, 1920, weighing 7 pounds, 12 ounces. When seen the first time at the age of 6 weeks the vomitus contained blood. On trying thick cereal feedings for a week, the vomited material contained more blood. The Strauss modification of the Rammstedt operation was performed. The result was gratifying, the vomiting ceased and the child gained in weight on breast milk feedings. On the sixth day, the little patient developed a cold with frequent coughing and sneezing. On the eighth day the nurse noticed that the stitches had sloughed and that the wound had partly opened with a partial evisceration. The intestines were immediately replaced and the wound closed. There was no rise in temperature, and after a few

6 Heubner: Lehrbuch der Kinderheilkunde, Ed. 3, Vol. 1, p. 218.

7. Ibrahim: Die Angeborene Pylorusstenose, Berlin, 1905. Ergebnisse d. Inn. Med. and Kinderh. 1:208, 1908.

8. Porter: Arch. Pediat. 36:385, 1919.

9. Sedgwick: Journal Lancet 37:43\%, 1917.

10. Lewis: J. A. M. A $\mathbf{7 5 : 2 3 2 ~ ( J u l y ~ 2 4 ) ~} 1920$.

11. Hill: J. A. M. A. 75:232 (July 24) 1920. 


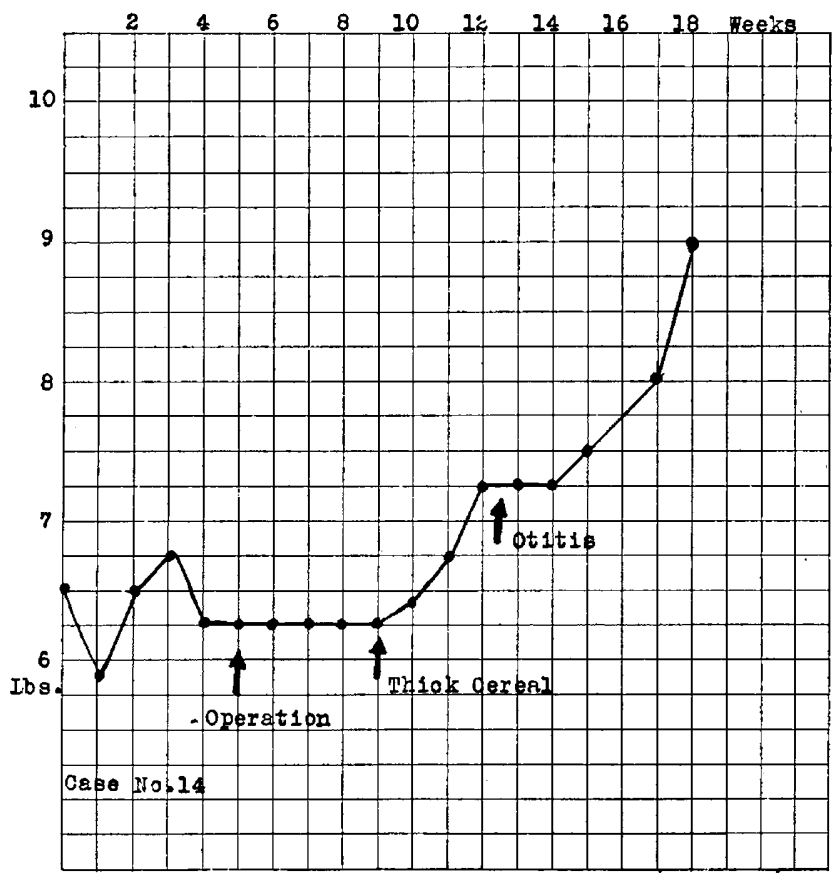

Figure 3.

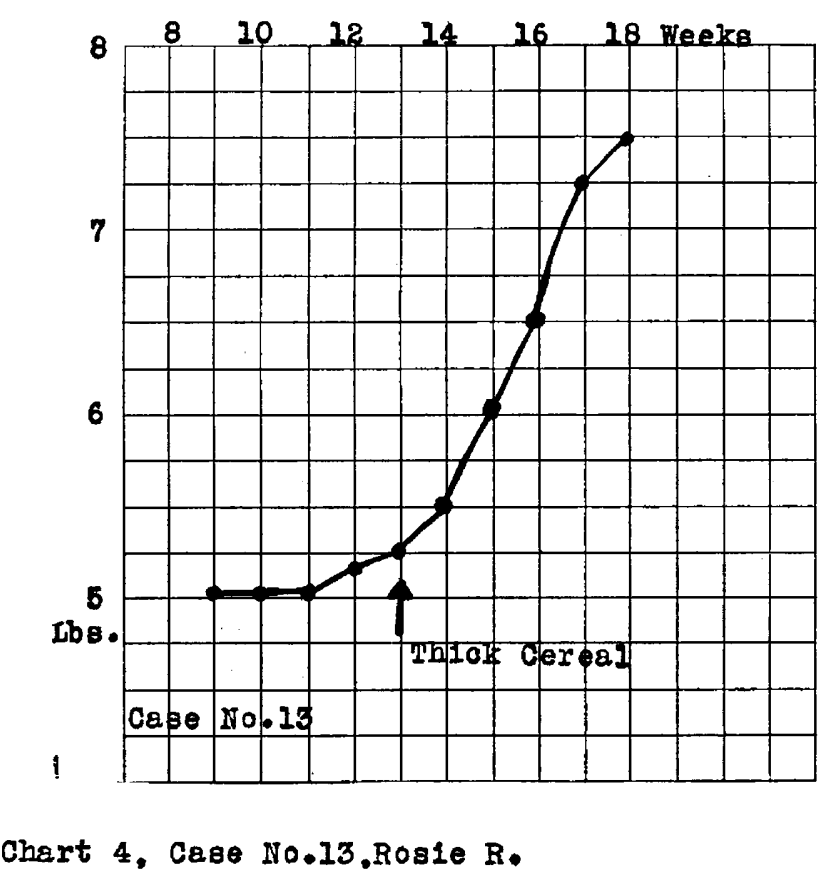

Figure 4. 
'weeks the child was sent to the Evanston Hospital. During the following weeks, there was more or less vomiting and the gain in weight was negligible. On the twenty-first day after operation the vomiting became projectile and incessant, the child became toxic and the bowels failed to move. The abdomen was soft, although intestinal peristalsis could be seen through the thin abdominal wall. The abdomen was reopened within twenty-four hours after the onset of severe symptoms. The skin incision was made parallel and lateral to the original one. A loop of small bowel had grown firmly adherent to the parietal peritoneum along the entire incision and was removed with difficulty. Laparotomy revealed numerous adhesions and bands. These were released and due to the moribund condition of the infant about 80 c.c. of uncitrated blood was given into the sinus. Recovery was very slow during the following two weeks. As more or less vomiting continued, barley flour paste made with breast milk was started two weeks after the laparotomy. The vomiting ceased at once and the child gained 7 ounces the first week and 1 pound the following week (Fig. 1). She is now 8 months old and weighs 17 pounds.

CASE 2.--Violet S. was seen for the first time Jan. 19, 1921, at the age of 4 months, weighing 5 pounds and 12 ounces. The Rammstedt operation had been performed at the age of 6 weeks. There had been no gain in weight since the operation. The athreptic infant was getting condensed milk, had an enteritis and bronchitis with a temperature of $101 \mathrm{~F}$. There was no vomiting. The child was given 50 c.c. of uncitrated blood intra-muscularly and fed breast milk. In the course of the following three weeks the infant gained 1 pound. February 7 severe vomiting, constipation and toxic symptoms rapidly developed. The abdomen was soft. Laparotomy was performed thirty-six hours after the onset of symptoms. The report of the surgeon, Dr. W. C. Danforth, follow's :

The child was extreme!y emaciated, the abdominal wall thin, moderately distended but without rigidity, showing very plainly distended coils of intestines. On opening the abdo. men, many adhesions were present, omentum to abdominal wall at the site of the previous scar, light adhesions of coils of bowel one to another and in the ileum volvulus involving five inches of bowel twisted sharply on its mesentery. The strangulated area of bowel was very dark in color, but showed slight improvement in color on relief of the volvulus. In the mesentery thrombotic enlarged veins were seen. The intestine below the area involved in the volvulus was flattened, resembling coils of tape. As the strangulated bowel, after the application of hot laparotomy pads for a few moments, showed a slight improvement in color, abdomen was closed.

The essentials of the convalescence are noted in Dr. Sauer's report. We were greatly and agreeably surprised at the recovery which the child was able to make.

The moribund infant was given 60 c.c. of tncitrated blood into the sinus. The recovery was slow during the following two weeks. February $2 \tau$ the infant was given barley flour paste made as follows: Skimmed milk, 12 ounces; water, 4 ounces; barley flour, $2 \frac{1}{2}$ ounces; dextri-maltose, 1 ounce. Boiled one hour. Two and one-half ounces in four feedings; three ounces breast milk in three feedings. The infant gained 8 ounces in the following week, 10 ounces the week after that. She now weighs over 10 pounds (Fig. 2).

CASE 3. (14).-Nancy B., was born Dec. 15, 1918, weighing 6 pounds 10 ounces. When seen the first time (Jan. 17, 1919) the infant had a temperature of $102 \mathrm{~F}$. besides manifesting the typical symptoms of stenosis. A tumor could not be palpated, and the child was having from three to four stools a day (the family physician having ordered 15 drops of milk of magnesia before each nursing). Dextrose-Ringer's solution was given by rectum and subcutaneously. A catherized specimen of urine contained much pus. albumin and hyalin casts. The temperature varied from 101-105 F. The Rammstedt operation was performed January 24. An average sized tumor was found. She received breast milk until February 22 (four weeks) without any influence on the vomiting or weight. As the bladder condition had cleared up and the temperature was normal or subnormal, it was considered safe to begin thick cereal feedings. This was done cautiously during the following week. The 
food was made as follows: Cow's milk or breast milk, 12 ounces; water, 8 ounces; barley flour, 2 ounces; dextri-maltose, 1 ounce. Boiled one hour. By the end of the first week of thick cereal feeding breast milk was discontinued entirely. She makle an uneventful recovery (Fig. 3).

These three cases show what complications may occur after operation, even when operation is performed by skilled surgeons. These cases fall in line with observations published by other observers.

A few remarks about operative cases may not be amiss. Fluids should frequently be given subcutaneously or by rectum before or immediately after the operation. Blood, intramuscularly or into the

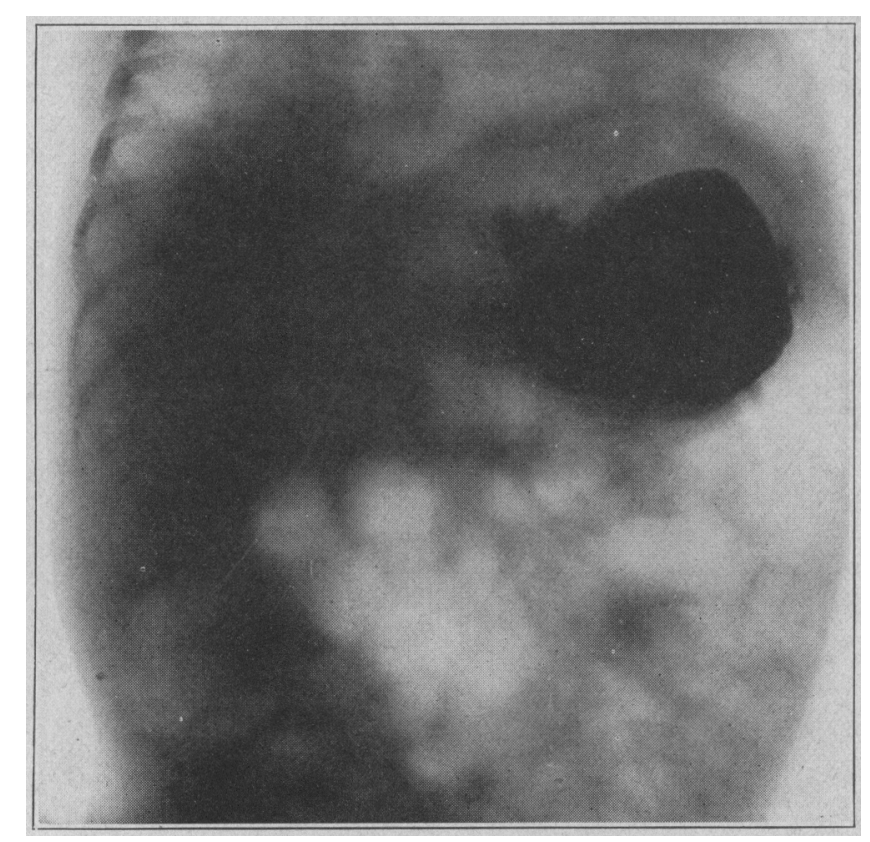

Fig. 5. Case 13. Series A.-Tiro hours after bismuth milk feeding (Strauss position).

sinus, is of unquestionable benefit in extreme cases. Breast milk should be given whenever available. If the supply is insufficient, albumin milk may be of value. Morgan ${ }^{12}$ and Goldbloom and Spence ${ }^{13}$ have detailed the postoperative management of Downes' cases.

Heubner, feeding breast milk to twenty-one infants with pyloric stenosis, had a mortality of 9.5 per cent.. Sedgwick, using the same method in forty-four cases, lost but one patient. ()f the eighty-three cases collected from the German literature by Ibrahim, the mortality

12. Morgan: Am. J. Dis. Child. 11:245 (Xarch) 1916.

13. Goldbloom \& Spence: Am. J. Dis. Child. 19:263 (Narch) 1920. 
was 22.9 per cent. Finkelstein and Meyer ${ }^{14}$ claim that no method of feeding will stop the vomiting in pyloric stenosis. On the other hand, Birk ${ }^{15}$ advocated the use of cornmeal gruel. In his book a weight chart shows very conclusively that the infant gained rapidly as soon as this food was substituted for breast milk. Porter, using my method of cereal feeding, got rapid cures in ten successive cases. Moll ${ }^{16}$ reports good results with cake-flour paste.

Thick cereal feeding is not a panacea for pyloric stenosis. There are undoubtedly cases which do not respond to the treatment ats

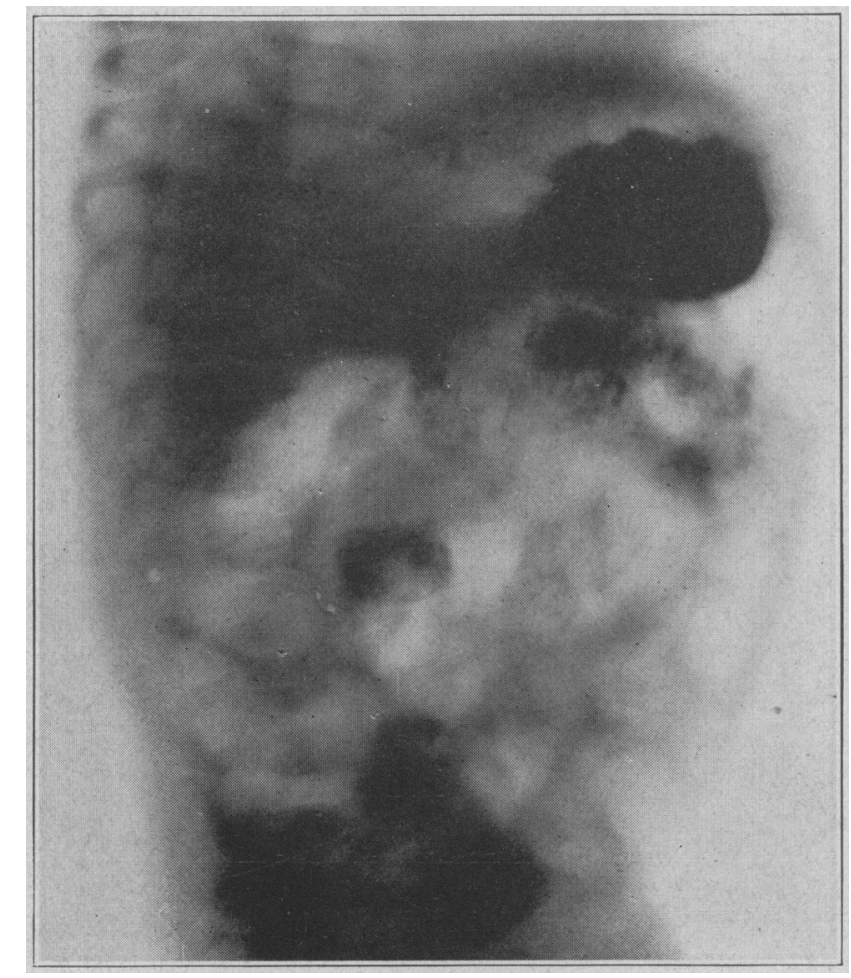

Fig. 6. Case 13. Series A.-Four hours after bismuth milk feeding (Strauss position).

expected. Sometimes this is the fault of the physician and not the patient. Several of my patients (Cases 6, 8, 18) wou'd doubtless have made more rapid progress if the proper precautions had been taken throughout the treatment. In favorable cases, the immediate decrease or cessation of vomiting and the rapidity of weight increase is very striking ( see table).

14. Finkelstein and Meyer: Deutsch. med. Wchnschr. 45:873 (Aug. 7) 1919.

15. Birk: (translated by Schlutz) N. Y. Rehman \& Co., 1916.

16. Moll: Ztschr. f. Kinclerh. 22:147, 1919. 
Success often depends on the proper preparation and administration of the thick cereal. It must be cooked thoroughly and be sufficiently thick to adhere to an inverted spoon. The influence of consistency is illustrated by the following two cases:

Case $4(6)$.-Nelson L., weight 8 pounds and 4 ounces at birth, was seen for the first time at the age of 3 months. Various perliatricians had seen him and had tried varions dietary measures. A tumor was palpable. One insisted that operation was necessary. Dr. H. F. Helmholz preserileel thick cereal feedings. There was no gain in weight and the projectile vomiting continued for ten days. On visiting the home it was found that the consistency of the food was

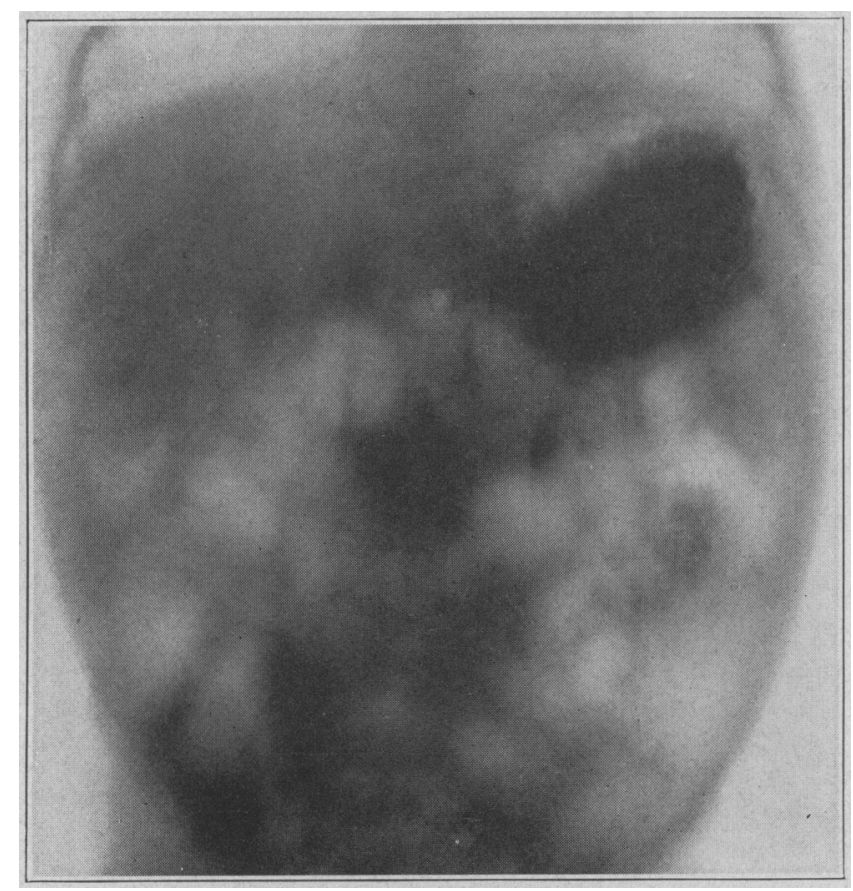

Fig. 7. Case 13. Series A.-Four hours after bismuth milk feeding. (Nothing has left the stomach).

too thin. When this error was corrected, the romiting immediately became less and the gain in weight was rapid. Peristaitic waves persisted for many weeks but all other symptoms of stenosis soon disappeared. The child now attends school and has never had a recurrence of symptoms. He is about 10 per cent. above the average weight for his height.

CASE 5. (16).-Thomas $X$., weighing 7 pounds and 14 ounces when first seen at the age of 6 weeks. presented a typical picture of stenosis. As the milk mixture the physician hacl ordered was considered adequate, the only change made in the diet during the first month was the addition of six tablespoonfuls of farina. This made the food sufficiently thick and the vomiting became very much less. He gained 17 onnces during the first month of this feeding. 
One part of cereal to seven parts of fluid (three of milk and four of water), boiled in a covered double boiler for an hour, usually makes a cereal of proper consistency. Such a food consists of about 15 per cent. cereal. Sugar and salt may be added. Most of the cases were started on a cereal as llows, and then the proportions were changed from time to time as rasion demanded: skimmed milk, 9 ounces; water, 12 ounces; fari or rice flour, 6 teaspoonsful; dextri-maltose, 3 ounces. Boil ai hour or more in a covered double boiler until thick. The consistency of the food requires careful supervision.

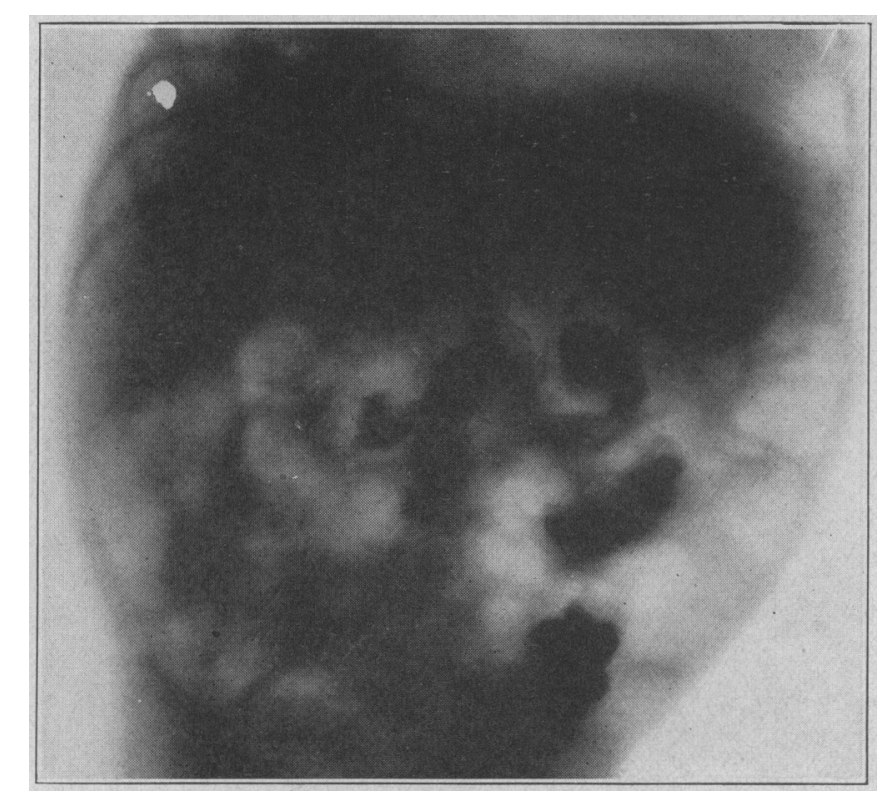

Fig. 8. Case 13. Series B.--Two hours after bismuth cereal feeding (Strauss position ).

A satisfactory way to give the food is to have the required amount of the prepared food in a cup immersed in a shallow saucepan containing hot water. By taking a little of the warm, thick cereal on the end of a narrow tongue depressor it can very easily be placed far back into the open mouth and scraped off with another tongue depressor. Porter recommends the use of a hygeia nipple with an enlarged hole. A great deal of patience is usually required the first few days, as the young infant often keeps the thick cereal in the mouth some time before swallowing it. At first, an hour or more may be required to give a feeding of a few tablespoonsful, but this difficulty is soon overcome in most cases. Twenty-one of my patients were taken care of in the home by the mothers. 
From two to six tablespoonsful of such cereal may be given six or seven times a clay. When breast milk is available, one may try giving one or more tablespoonsful of the cereal before the nursing or bottle breast milk feedings. If such a régimé proves unsuccessful, four thick cereal feedings and three brud.t milk. sedings should be tried for a few days. If this fails to stop the vom ing and loss in weight, then all feedings should consist of the thick a $a$ l. In severe cases, the latter procedure shoula be instituted at once. f . ly a ailable breast milk should be added to the cereal replacing the cow's milk. The child should be placed on its right side for a few hours following the feed-

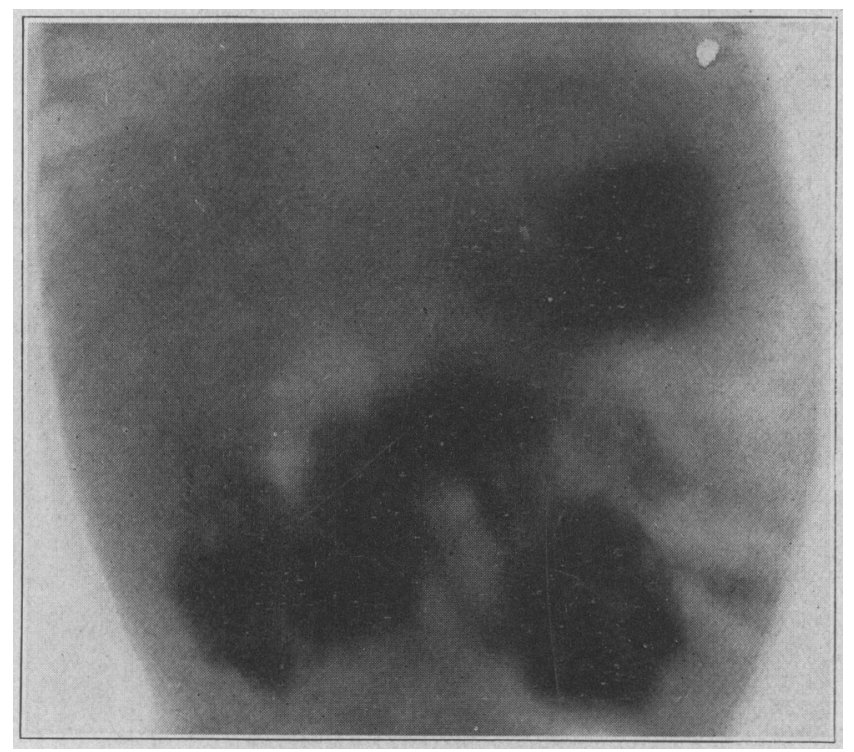

Fig. 9. Case 13. Series B.-Four hours after bismuth farina feeding (Strauss position).

ing. It must be handled very little and should rest on a medium soft pillow. In my last twenty-four cases the stomach was not washed out, in fact, very little fluid was given by mouth for the first few weeks. Water must be furnished at regular intervals, preferably by retention enema, by the Murphy drip method or by hypodermoclysis.

After thick cereal feedings have been persisted in for some time, liquid foods also pass through the pylorus. This interval varies in different cases-it usually requires at least from five to eight weeks before an appreciable amount of liquid food can be given without being vomited. The safest way to proceed when this time has apparently arrived is to substitute for one and later for several of the thich cereal feedings ordinary milk mixtures. If romiting is not provoked in this 
way the child can be put on a milk mixture without much further trouble in spite of persistent peristaltic waves and palpable tumor. During the past few years rice flour and barley flour have been used in place of or in conjunction with farina.

Resulits in Thirty-Five Cases of Pyloric Stenosis

\begin{tabular}{|c|c|c|c|c|c|c|c|c|}
\hline No. & Name & $\begin{array}{l}\text { Age } \\
\text { in } \\
\text { Wks. }\end{array}$ & $\begin{array}{l}\text { Weight } \\
\text { in Lbs. } \\
\text { and Oz. }\end{array}$ & $\begin{array}{l}\text { Weight } \\
1 \text { Mo. } \\
\text { Later }\end{array}$ & $\begin{array}{c}\text { Ounces } \\
\text { Gain in } \\
\mathbf{1} \text { Mo. }\end{array}$ & $\begin{array}{l}\text { Treat- } \\
\text { ment }\end{array}$ & Result & Remarks \\
\hline 1 & Ruth F & 6 & 5.0 & 6.12 & 28 & $\mathrm{C}, \mathrm{Br}$. & Recovery & Hospital \\
\hline 2 & Steph. W. & 3 & $9 . \delta$ & 10.0 & 8 & C, B & Recovery & Home : nd mother \\
\hline 3 & Lloyd T. & 13 & 7.8 & 9.14 & 28 & $\mathrm{C}$ & Recovery & Home and mother \\
\hline 4 & Harry $\mathrm{H}$. & 4 & 6.4 & 8.0 & 28 & $\mathrm{C}$ & Recovery & Home and mother \\
\hline 5 & Claren. $\mathbf{T}$. & 14 & 10.0 & 11.4 & 20 & C & Recovery & Home and mother \\
\hline 6 & Nelson L. & 14 & 8.8 & 9.8 & 16 & C & Recovery & Home and nurse \\
\hline 7 & Robt. D. . & 10 & 6.8 & 7.12 & 20 & $\mathrm{C}$ & Recovery & Home and mother \\
\hline 8 & John A... & 7 & 8.4 & 8.4 & 0 & $\mathrm{C}, \mathrm{Br}$. & Recovery & Home and nurse \\
\hline 9 & John B. . & $T$ & 6.12 & 6.12 & 0 & C & Improved & Hospital \\
\hline 10 & Betty $\mathrm{H}$. & 4 & 5.4 & 6.4 & 16 & C & Recovery & Home and nurse \\
\hline 11 & Donald F. & 3 & 6.9 & 6.12 & 3 & $\mathrm{C}, 0$ & Recovery & Home and nurse \\
\hline 12 & Betty M. . & 22 & 11.4 & 12.12 & 24 & $\mathrm{C}$ & Recovery & Home and nurse \\
\hline 13 & Rosie R. & 12 & 5.6 & 7.2 & 34 & $\mathrm{C}$ & Reeovery & Hospital \\
\hline 14 & Naney B. & 5 & 6.4 & 6.4 & 0 & $0, \mathrm{C}$ & Recovery & Hospital \\
\hline 15 & Betty C. & 11 & 7.0 & 7.0 & 0 & C, 0 & Died & Hospital \\
\hline 16 & Thos. N. & 6 & 7.14 & 8.15 & 17 & C & Recovery & Home and mother \\
\hline 17 & Blain B. . & 12 & 9.8 & 11.2 & 26 & C & Recovery & Home and mother \\
\hline 18 & Norm. S. . & 12 & 7.15 & 9.7 & 24 & $\mathrm{C}$ & Recovery & Home and mother \\
\hline 19 & Virgin. D. & 14 & 7.12 & 9.8 & 28 & C & Recovery & Home and mother \\
\hline 20 & Henry $\mathbf{D}$. & 5 & 6.8 & 9.14 & 54 & C & Recovery & Hospital \\
\hline 21 & Edw. P. & 9 & 7.0 & & & C & Died & Hospital \\
\hline 22 & James B. & 13 & 8.12 & 10.8 & 28 & $\mathrm{C}$ & Recovery & Home and mother \\
\hline 23 & James C. & 8 & 7.3 & 10.2 & 47 & C & Recovery & Home and mother \\
\hline 24 & Warren $\mathrm{P}$. & 7 & 6.8 & 9.10 & 50 & $\mathrm{C}$ & Recovery & Home and mother \\
\hline 25 & John W... & 5 & 6.12 & 8.8 & 28 & C & Recovery & Home and mother \\
\hline 26 & Chas. S. . & 5 & 9.1 & ..... & . & C, 0 & Recovery & Hospital \\
\hline 27 & Ward $P$. & 3 & 6.14 & . & 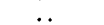 & $C, 0$ & Recovery & Hospital \\
\hline 28 & William $\mathbf{M}$. & 4 & 6.9 & 7.11 & 18 & $\mathrm{C}$ & Recovery & Home and mother \\
\hline 29 & Jerome R. . & 6 & 6.6 & & & $c, 0$ & Died & Hospital \\
\hline 30 & John Be... & 9 & 10.8 & 12.4 & 28 & $\mathrm{C}$ & Recovery & Home and mother \\
\hline 31 & Alene $\mathrm{T}$. & 4 & 6.14 & & & $\mathrm{C}, 0$ & Recovery & Hospital \\
\hline 32 & Everett W. & 12 & 8.4 & 7.12 & 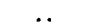 & $\mathrm{C}$ & Rcoovery & Hospital \\
\hline 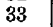 & $\overline{\mathrm{W}} \mathrm{m}$ & 5 & 6.9 & 7.12 & 19 & $\mathrm{C}$ & Recovery & Home and mother \\
\hline 34 & Clair W. & 5 & 6.8 & 7.8 & 16 & C & Recovery & Home and mother \\
\hline & Edw. N. ............ & 7 & 6.4 & 7.0 & 12 & $\mathrm{C}$ & Reovery & Home and mother \\
\hline
\end{tabular}

C, thick cereal; 0, operation; Br., breast milk.

This report, covering thirty-five cases of pyloric stenosis, gives the results of all cases seen from 1914-1921 (see table). In a previous communication, ${ }^{17}$ the first twelve cases were reported somewhat in detail. Twenty-two of the patients gained a pound or more during the first month. Twenty- four gained from the start. Eighteen were taken care of in the home by the mother. One of my thirty-five patients died while receiving thick cereal. This boy (Case 21) was admitted to the hospital when 9 weeks old weighing 7 pounds. The vomiting decreased as soon as the thick cereal was begun. There was no gain in weight. The child died suddenly on the ninth day. No necropsy was obtainable.

Operative Cases.-Five of the seven operated patients recovered.

17. Sauter: Arch. Pediat. 35:385, 1918. 
CASE 7 (11).-This case is of interest because peristaltic waves were never visible, nor could a tumor be palpated. The projectile vomiting began when the child was 2 weeks old. The vomiting occurred after most nursings. During the first few days, a tablespoonful or more of thick cereal was given before the nursings. As this was without effect, three thick cereal feedings were given, alternating with four nursings. The cereal was retained better than the breast milk, but the weight remained stationary. After another week, six cereal feedings were given, the breast milk being added to the thick cereal. In spite of the best nursing care, decrease in the vomiting and from one to three bowel movements a day, the child failed to gain. The vomiting occurred a few times a day but was very forceful. At operation, a tumor much larger and harder than usually encountered, was incised. The child made an uneventful recovery, being weaned at nine months. Case 14 was one of pyelocystitis

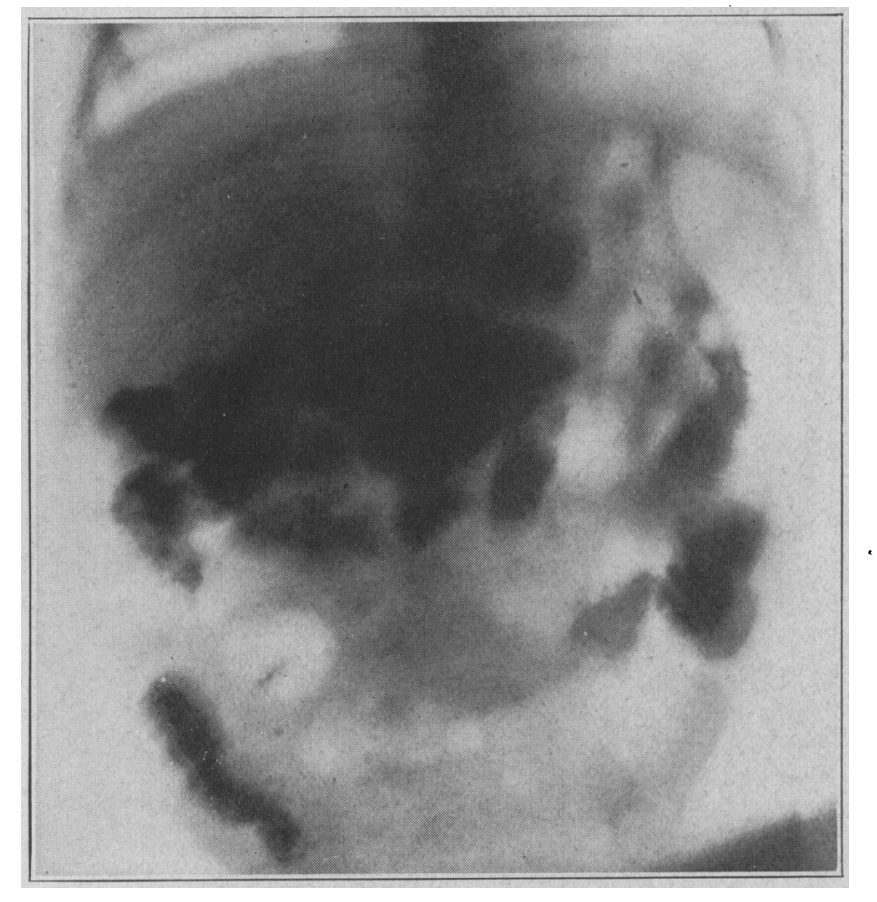

Fig. 10. Case 13. Series B.-Four hours after bismuth farina feeding (stomach nearly empty).

complicating the pyloric stenosis. When first seen, the baby was 5 weeks old and weighed 6 pounds 4 ounces. Her temperature was above $104 \mathrm{~F}$. She was given fluids subcutaneously and by rectum and the Strauss modification of the Fredet-Rammstedt operation was performed a few days later (temperature $102 \mathrm{~F}$.) The vomiting continued for four weeks after operation, although the cystitis had entirely cleared up (temperature normal for several weeks). Having received breast milk for four weeks after operation without a gain in weight, thick cereal feedings were gradually substituted. The vomiting ceased within three days and the child gained 18 ounces during the first month of thick cereal feeding. The operation in this case was inadequate (Fig. 3).

CASE 7. (15).-Betty C., was 11 weeks old and weighed 7 pounds when admitted to the hospital. She was a patient of Dr. H. F. Helmholz. Her 
admission temperature of $102 \mathrm{~F}$. was probably due to "influenza." This was followed by a purulent otitis media and a subsequent bronchopneumonia. The vomiting was not very severe, but the roentgen ray showed that the food did not leave the stomach entirely at the end of four hours. As the weight remained stationary during the fifty days of thick cereal feeding, the FredetRammstedt operation was performed under local anesthesia. The child vomited large quantities of blood after operation. She died three days later in spite of two blood transfusions. There was no necropsy.

CASE 8 (26).-Chas. S., was referred by a pediatrician who had tried the thick cereal without result. The child was 5 weeks old and weighed 9 pounds 1 ounce ( 8 ounces less than at birth). He lost 9 ounces during the twelve days he was under my care. As he seemed to be suffering severe pain, the Strauss modification of the Fredet-Rammstedt operation was performed. Recovery was uneventful.

CAs: 9 (27).-Ward P., had projectile vomiting on the fourth day after birth. The vomiting subsided after a few days and the child regained his birth weight ( 8 pounds 2 ounces) on the sixteenth day when he was circumcised. That night the projectile vomiting was much increased and continued to be very forceful. Peristaltic waves were not very prominent. Roentgenograms taken four hours after a thick cereal feeding showed that very little food passed beyond the pylorus. The child lost 21 ounces in six days. In spite of lavage, bottle breast milk feedings and attempted duodenal feedings the weight continued to decrease rapidly. The Fredet-Rammstedt operation was performed on the twenty-second day. The tumor was not very large and not very hard. Recovery was rapid on breast milk.

CASE 10 (29).-Jerome R., never regained his birth weight as the vomiting began a few days after birth. He was first seen when 6 weeks old, weighing 6 pounds 6 ounces. Thick cereal feedings had been attempted in the rural home by another pediatrician under rather adverse circumstances. When admitted into the hospital his general condition was poor. As he frequently refused to swallow the food and often appeared drowsy he was operated on eleven days after admission. He died rather suddenly two days after operation. No necropsy was obtainable. There were no manifest complications.

CAs: 11 (31).-Alene T., was admitted when 4 weeks old, weighing 7 pounds ( 5 ounces less than at birth). Thick cereal feedings were given for about a week, during which time she lost 6 ounces. As the vomitus frequently contained appreciable quantities of brown blood, she was operated on. She gained rapidly the following week, then a pharyngitis developed which was accompanied by other complications. (For subsequent details see above.)

Some clinicians and surgeons consider the roentgen ray an aid in diagnosis. Others use roentgenography to determine the degree of patency of the pylorus. Downes and Holt ${ }^{18}$ consider it of no diagnostic value in typical cases. Strauss believes that a "fluoroscopic examination shows definitely not only if there is a congenital pyloric stenosis, but also if the patient should be treated medically or surgically. If from 70 to 80 per cent. of the bismuth milk goes through within four hours, there will undoubtedly be recovery, irrespective of any clinical symptoms or tumor." The estimation of the amount left in the stomach at the end of four hours requires a lot of experience, to say the least.

Our experience with the roentgen ray in this connection is of exceptional interest. The first case which was subjected to such examination

18. Holt: J. A. M. A. 68:1517 (May 26) 1917. 
is reported here in detail. This girl baby (Case 13) is undoubtedly the most interesting case of the who'e series. Pictures were taken also of Cases 15, 16, 20, 27, 31 and 32. Pictures were taken with bismuth milk (Series A) and a few days later with bismuth thick cereal (Series B). The only change made in the formula was the addition of sufficient farina to make it thick. Roentgenograms were made with the patient in the position advocated by Strauss, also with the infant lying on the back. Roentgenograms were taken immediately after the feedings, also one, two and four hours later.

The first series shows that most of the bismuth milk was still in the stomach at the end of four hours, irrespective of the position of the child. In the second series, the same food, thickened with farina, quickly passed into the duodenum and the stomach was nearly empty at the end of four hours. This infant, according to Strauss' standard, would need operation. She was not operated on, but was given thick cereal and gained 34 ounces in thirty days (Fig. 4). She died of gonorrheal peritonitis some months later. A typical, cartilaginous hypertrophy of the pylorus was found, ${ }^{19}$ in spite of the fact that she had been absolutely free from feeding disturbance.

When the diagnosis of pyloric stenosis is made the author tells the parents the nature of the ailment and that an operation may be necessary, but that thick cereal feedings will be tried for a short time to see whether the symptoms improve. The general condition of the patient, the stools, urine, vomitus, weight, food and feeding technic are closely watched. The presence of a palpable tumor or the size of the peristaltic waves have no bearing in making a decision. The weight, severity of vomiting, paucity of fecal materia!, complications and the general condition of the patient are the factors that determine how long thick cereal feedings may be tried. Fluids, preferably 6 per cent. dextrose Ringer's solution, are always given regularly by rectum or subcutaneously. If, after a thorough trial (from one to two weeks) the vomiting fails to subside, if the weight fails to increase, or if the general condition of the child gets worse, operation is resorted to. In some cases conditions may be such that early operation may be advisable, for example, when infants come under observation in a very emaciated state and fail to respond immediately to the treatment.

19. Ibrahim, Wernstedt, ${ }^{20}$ Bloch, ${ }^{21}$ Batten, ${ }^{22}$ Simon ${ }^{23}$ and others have reported cases of known pyloric stenosis in which the patient died months or years after recovery without operation, but in which the cartilaginous tumor persisted.

20. Wernstedt: Jahrb. f. Kinderh. 674, 1907.

21. Bloch: Jahrb. f. Kinderh. 337, 1907.

22. Batten: Lancet 1511, 1899.

23. Simon: Jahrb. f. Kinderh. 331, 1911. 
With so much still unexplained about the mechanism of the normal pylorus, it is impossible to give a satisfactory explanation of how the thick cereal passes into the duodenum in case of pyloric stenosis while the same food thinned out (to reduce its consistency) is promptly vomited. Moritz ${ }^{24}$ found that in the adult solid food inhibited, and water stimulated gastric peristalsis. Schüle ${ }^{25}$ found fluid foods to increase the motility of the stomach. If one watches the events with the fluoroscope after ingestion of bismuth thick cereal it is seen that the mass gravitates to the pylorus and that more material passes through in a given time than with bismuth milk.

\section{SUMMARY}

1. The use of thick cereal in thirty-five cases of pyloric stenosis brought about a rapid gain in weight in twenty-four cases and was effective in twenty-eight of the thirty-five cases.

2. The preparation and administration of the food are important.

3. Patients should be operated on if the thick cereal fails to bring about improvement in from one to two weeks. Under certain conditions, one should not wait too long before operation.

4. Complications following operation are not infrequent.

5. Thick cereal feedings may be valuable when vomiting continues after operation.

\section{CONCLUSION}

In cases of pyloric stenosis proper medical treatment, supported, when necessary, by proper operative treatment, will give the best results.

24. Moritz: Ztschr. f. Biol. 42:572, 1901.

25. Schüle: Ztschr. f. klin. Med. 29:73, 1896. 